\title{
A versatile genetic tool: haploid cells
}

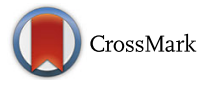

\author{
Yanni Li and Ling Shuai ${ }^{*}$ (1)
}

\begin{abstract}
Haploid cells are excellent tools to study gene function as they contain a single copy of the genome and are thus unable to mask the effect of mutations. Recently, haploid embryonic stem cells, which are capable of self-renewal and potentially differentiating into other cell types despite having only one set of chromosomes, have been established in several species. These unique haploid cells allow us to seek recessive gene functions in mammals, and have had a profound influence on the field of genetic screening and drug target identification. In this review, we briefly introduce advances and breakthroughs in haploid cell line research and broadly discuss the versatile application thereof.
\end{abstract}

Keyword: Haploid, Pluripotency, Diploidization, Genetic screening

\section{Background}

In evolutionary terms, almost all cells in sexual organisms are diploid, with haploid cells, which cannot further divide, being restricted to gametes. Haploid cells in yeast and plants can show gene mutation phenotypes without any allelic backup, so are utilized extensively in genetic engineering [1]. Although haploid cells in animals have been explored since the 1970s, it was not until 2009 that the first vertebrate haploid embryonic stem cell (haESC) line was developed. This cell line was generated from Medaka fish embryos and introduced a brand new system for analyzing recessive phenotypes in vertebrates [2]. Two years later, mouse haESCs were established, thereby initiating genetic screening in mammals with haploid cells [3, 4]. After this, monkey [5] and rat [6] haESCs were respectively derived, raising the feasibility of using haploid cells in other mammalian species for genetic studies. Recently, human haESCs were achieved from chemically activated human eggs, thus facilitating the research of genetic diseases and

\footnotetext{
* Correspondence: Ishuai@nankai.edu.cn

State Key Laboratory of Medicinal Chemical Biology, Nankai University, College of Pharmacy, Tianjin 300350, China
}

gametogenesis in humans $[7,8]$. Compared to previous near-haploid tumor cells [9], haESCs have intact genomes which lack mutations [10] and are pluripotent to three germ layers both in vitro and in vivo $[11,12]$. Besides differentiation potential, haESCs have special reproductive functions like gametes, which yield transgene delivery from cells to animals via introcytoplasmic injection $[12,13]$. What is more, haESCs have unlimited self-renewal abilities and are receptive to advanced gene editing methodologies. This allows these cells to generate homozygous genotypes containing only one set of chromosomes [14], thus making them a perfect tool to target gene functions associated with recessive traits.

In this review, the properties of haESCs and recent breakthroughs associated with their use in genetic screening are introduced. Key unsolved issues involving haESCs, as well as their future application in lineage specific gene function discovery, are raised.

\section{Identity of haploid cells}

haESCs express specific pluripotent genes and are able to form embryoid bodies and teratomas. They also share some common features with conventional diploid ESCs, such as colony morphology, unlimited self-renewal ability, and pluripotency. When injected into a blastocyst, mouse haESCs can contribute to the chimera through germline transmission [15]. Except for pluripotency, rodent haESCs are proven to be reproductive by replacing the genome with gametes. Intracytoplasmic injection of androgenic haESCs could support full-term development of the embryos in mice [12] and rats [6] (Fig. 1a). Additionally, substituting maternal pronuclei of zygotes with parthenogenic haESCs was shown to result in the birth of mice that retained maternal genetic and epigenetic identities [13] (Fig. 1b). Uniparental embryos cannot develop to term because the contributions of maternal and paternal genomes, although necessary, are not represented equally [16-18]. There are more than 80 imprinted genes in humans and mice [19]. One key imprinted gene cluster affecting development is Igf2-H19 [20], which is regulated by differentially methylated regions (DMRs). The epigenetic states of haESCs are 
a

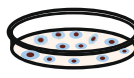

Early passage AhaESCs

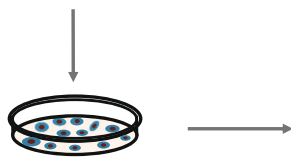

Late passage AhaESCs

b

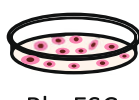

PhaESCS

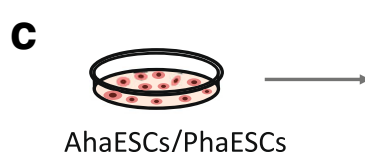

AhaESCs/PhaESCs
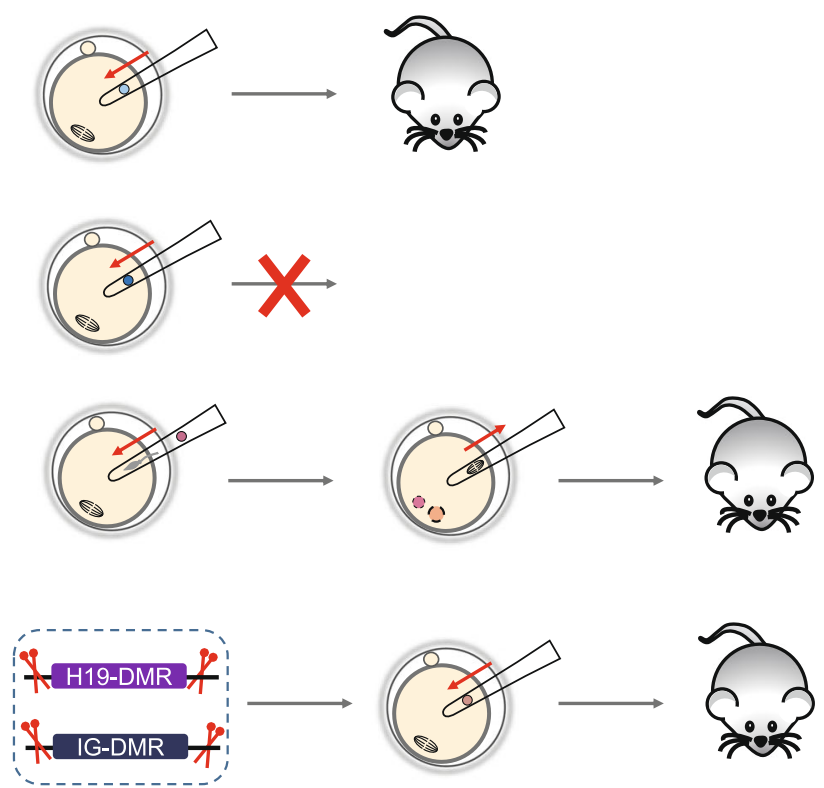

Fig. 1 Strategies to generate offspring with haESCs. a Intracytoplasmic injection of androgenic haESCs (AhaESCs) in early and late passages. AhaESCs can produce live offspring only in early passages, because of the loss of paternal imprinting in long-term cell culture processes. This reduces developmental potential of AhaESCs. b By replacing the female pronucleus with parthenogenic haESCs (PhaESCs), the fertilized zygote can produce healthy progeny. c By knocking out the H19-DMRs and IG-DMRs of haESCs (AhaESCs and PhaESCs), genetically modified haESCs can efficiently produce mice via intracytoplasmic injection. DMR differentially methylated region, haESC haploid embryonic stem cell

inherited from the gametes. This guarantees their development during the intracytoplasmic injection processes [21]. However, the developmental ability of these haESCs diminishes significantly after long-term cell culture due to the loss of imprinting (such as H19-DMRs). By knocking out H19-DMRs, androgenic haESCs can stably retain their developmental potential [22, 23] thereby offering a promising option in the production of transgenic animals via intracytoplasmic injection (Fig. 1c). Based on this strategy, two groups separately converted the state of parthenogenic haESCs to the paternal epigenetic-like state using H19-DMR and IG-DMR knockout systems (Fig. 1c). Full-term offspring were then generated via intracytoplasmic injection of these modified parthenogenic haESCs [24, 25]. For primate species, haESCs exhibit typical characteristics of pluripotent stem cells [5], but more investigation is needed to determine whether primate haESCs have similar reproductive functions to rodent haESCs.

Medaka fish haESCs can maintain the haploid status in multiple phases of differentiation [2], while mammalian haploid cells undergo diploidization during the culturing and differentiation processes. This raises a question about the duration and ability of haESCs to maintain their haploid state during mammalian differentiation. Shuai et al. [26] illustrated that mouse haESCs retained their haploidy and pluripotent states in both epiblast and neuronally differentiated stem cell stages. Similar results were also found in human haESCs [7], indicating that mammalian haploid cells have great potential in various lineage-specific genetic screening applications [10]. Another type of mammalian haploid cells can be observed through the study of near-haploid human tumor cells. Long before the establishment of authentic human haESCs, near-haploid cell lines had been derived from leukemia and solid tumors [27]. This cell line showed great advantages in screening for drug resistance or disease-related genes. However, like other cancer cells and thus posing a potential risk in their application, near-haploid cells tolerate many copy-number variations in their genome.

\section{Instability of the mammalian haploid genome}

The derivation of mammalian haESCs failed almost 30 years ago due to genome instability. The phenomenon of diploidization was found during the first attempt at mouse haESC establishment [28]. The development of fluorescence-activated cell sorting (FACS) technology made it possible to enrich for haploid cells and helped to derive the first mouse haESCs [3]. Some of the haESCs would spontaneously diploidize in daily culture, so periodical FACS was indispensable for haploid cell enrichment (Fig. 2a). Mouse haESCs require more frequent sorting than primate haESCs; perhaps because mouse ESCs proliferate at a higher rate. However, the exact mechanism remains unclear. Generally, when performing FACS, haESCs are stained with Hoechst 33342 and sorted using a 355$\mathrm{nm}$ ultraviolet (UV) laser. However, DNA-binding dyes 


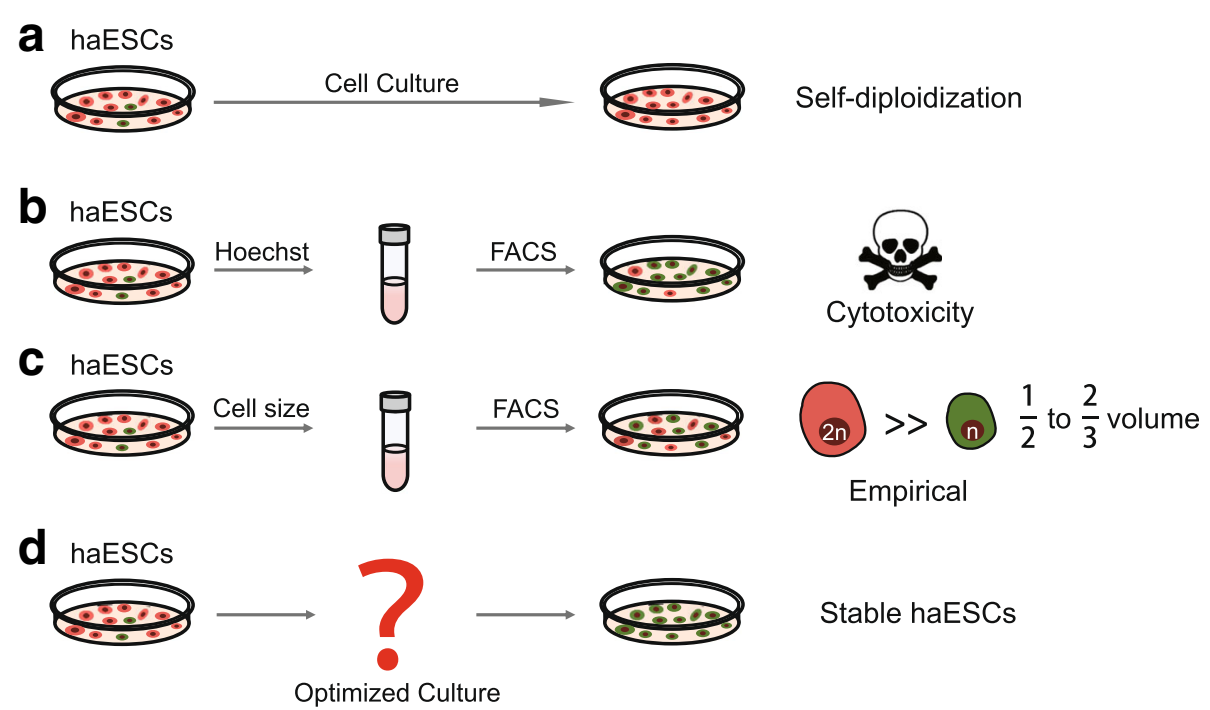

Fig. 2 Optimizing haESC culture and enrichment systems. a During daily cell culture, haESCs undergo severe self-diploidization thus preventing their application in genetics. b Although haESC concentrations can be enriched using the Hoechst 33342 sorting method, the effect of Hoechst 33342 is toxic and does great harm to haESCs. c Since haploid ESCs are half to two-thirds the size of diploid ESCs, they can be sorted according to their physical parameters. However, this strategy is subjective and difficult to judge. $\mathbf{d}$ An optimized culturing system which allows for the perpetual maintenance of haESCs is needed. FACS fluorescence-activated cell sorting, haESC haploid embryonic stem cell

and UV activation are harmful to the cell and affect the likelihood of survival (Fig. 2b). In order to achieve haploid purification, some groups have tried to develop an alternative method to DNA straining. Haploid ESCs are half to two-thirds the size of the diploid cells [29] meaning that the diameter of haESCs ranges from 10.0 to $15 \mu \mathrm{m}$ at the G1 phase [30]. Taking advantage of physical differences in diameter and using diploid ESCs as controls, it is easy to distinguish the haploid cell population using forward scatter (FSC) and side scatter (SSC) on a scatter plot generated from sorting of these cells [31] (Fig. 2c). Although the enrichment of haESCs by cell size circumvents the toxicity due to the DNA dye, this method is subjective and requires experience to gait the haploid population precisely.

Although optimization of the FACS method is needed, describing the mechanism associated with selfdiploidization is of greater importance (Fig. 2d). An accepted hypothesis is that abnormal cell cycle regulation causes cells to skip the $M$ phase and re-enter the G1/S phase so as to duplicate DNA. Takahashi et al. [32] developed a culture medium using a small molecular inhibitor of the Wee1 kinase in order to accelerate the G2/M phase transition and prevent cells from re-entering the G1/S phase. In this culture medium, haploid cells could last at least 4 weeks without FACS, providing supportive evidence that cell cycle regulation may be a reason for diploidization. Recently, an interesting study showed that the duration of the metaphase in haESCs is significantly longer than that in diploid ESCs, while a chemically induced delay in mitosis strengthened the observation of diploidization [33]. Meanwhile, the consistent maintenance of haploidy in primates and humans is greater than that observed in rodents. While the hypothesis associated with this finding needs further validation, proliferation kinetics is thought to be relevant to self-diploidization. Nevertheless, the specific pathway(s) regulating diploidization has not yet been found. Since diploidization compromises the application capacity of haESCs, it is important that the genomes of haESCs are stabilized.

\section{Genetic screening}

Genetic screening is the prominent application of haploid stem cell technology. Saccharomyces cerevisiae was used as a model organism to study haploid gene function before the derivation of haESCs [1]. However, due to species specificity, this approach cannot be directly applied to mammalian systems. Although the human genome project has successfully sequenced all 3 billion chemical units and identified approximately 20,00025,000 genes in the human genome, their relevant functions are yet to be elucidated fully and require further study. Global genomic screening has therefore been widely used in mammalian ESCs in order to clarify gene function in many biological procedures. However, it is difficult to obtain homozygous mutations in diploid ESCs. Additionally, heterozygous genotypes may have no impact on their phenotype for the homologous allele complement. This means that diploid genomes hamper the study of recessive genetic conditions. Since haploid 
cells only carry one set of chromosomes, they exhibit corresponding phenotypes in the presence of a mutation. Genetic screening in mammalian cells often directly promotes medicinal and pharmacological research. Currently, it is difficult to obtain double homogeneous allele mutations through genome editing techniques. This hinders the generation of homozygous gene knockout libraries. The use of haESCs, however, can overcome this obstacle.

Typically, genetic screening aims to obtain loss-offunction phenotypes through allele mutation. Genomic engineering is applied to produce mutant libraries through transposon-mediated insertion or nucleasemediated targeting modification technologies-including piggyBac, Clustered regularly interspaced short palindromic repeats/Cas (CRISPR/Cas), and transcription activator-like (TAL) effector nucleases (TALENs) [34]. Once screened and tested, specific mutated cells are said to have been generated. Hitherto, through gene screening on haploid cell lines, basic studies including DNA repair, drug toxicity, X-chromosome inactivation, cell differentiation, and human clinical diseases have been investigated separately $[3-5,7,8,23,29,35-43]$ (Fig. 3). Primate haESCs can maintain haploidy in long-term culture, which makes them good resources for gene function research $[5,7,8]$. All of the established mammalian haploid cells, including near-haploid human tumor cells, have been applied in whole-genome genetic screening at the cellular or organism level, and many accomplishments have been achieved to date. Leeb et al. [37] found that Zfp706 and Pum1 were key regulators governing differentiation of naive stem cells by screening mutated haESCs. Recent gene editing techniques facilitated the efficient utilization of haESC resources, such as CRISPR/ Cas9 knockout libraries, to acquire offspring carrying multiple heterozygous mutations [23, 44]. In addition, gene trapping with a piggyBac transposon is a more efficient approach in the genetic screening of haESCs, because it allows more precise assessment of the integration site than when using CRISPR/Cas or TALENs [6, 45]. Taken together, gene screening in haESCs boosts the basic and clinical research fields of developmental biology and regenerative medicine [34]. This holds great value in the study of cancer, species evolution, biomolecular interactions, lineage specification, and signal pathways.

\section{A platform to study X-chromosome inactivation}

Along with many genetic screening traits, haESCs are ideal tools to study X-chromosome inactivation (XCI). In diploid cells, the expression ratio of $\mathrm{X}$ chromosomes to autosomes $(\mathrm{X}: \mathrm{A})$ is $1: 2$, while the ratio of $\mathrm{X}: \mathrm{A}$ is $1: 1$ in haploid cells [29]. XCI is a mammalian-specific, sophisticated process involved in epigenetic modifications and developmental processes. There are three types of XCI in mammals: XCI through imprinting, random XCI which happens in female development, and transcriptionally inactivated XCI during meiotic prophase I in males [46]. In mammals, dosage compensation occurs in $\mathrm{XX}$ females with the expression of the long noncoding $\mathrm{X}$-inactivation-specific transcript (Xist) which randomly inactivates one of the two $X$ chromosomes [47]. Overexpression of Xist can also initiate XCI.

Monfort et al. [35] used a dox-inducible Xist overexpression system to screen for key regulators in XCI. They identified a RNA-binding protein SPEN which is required for Xist RNA localization and recruitment of chromatin modifications. This system serves as a good example of using haploid ESCs when studying gene-

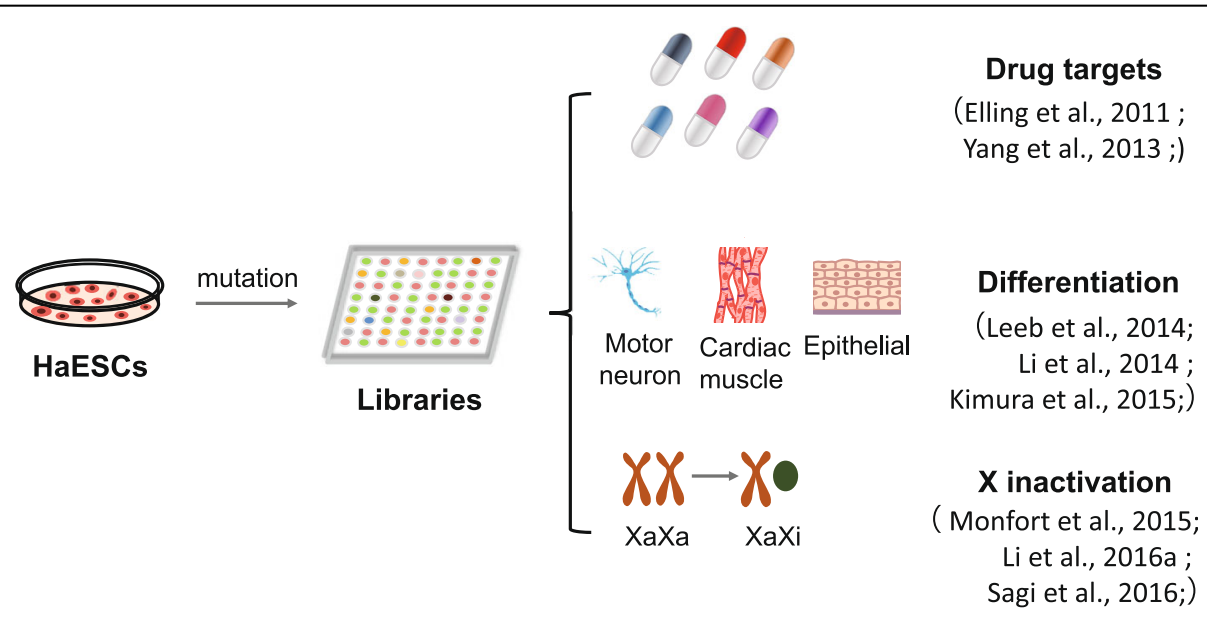

Fig. 3 Application of haESCs in multiple types of genetic screening. Since haESCs contain a haploid copy of the genome, it is easy to obtain homozygous mutant libraries through transposon or viral systems. To date, mutant haESC libraries have been exploited in various targeted gene screening systems in order to track cell fate. Such systems include factors such as toxic resistance $[4,5]$, cell differentiation $[6,37,48]$, and X-chromosome inactivation [7, 35, 36]. haESC haploid embryonic stem cell 
silencing pathways and epigenetic modifications. Li et al. [36] generated mouse-rat allodiploid ESCs through fusion of haploid ESCs between the two species. They reported an interesting phenomenon in that the allopolyploid cell lines exhibited special gene expression patterns and mouse-specific XCI during differentiation. Furthermore, they systematically analyzed the bulk RNA-seq data, and found 146 unknown mouse genes potentially escaping $\mathrm{XCI}$ in the allodiploid differentiated somatic cells. Therefore, haESCs offer a brand new platform to study the XCI process in mammalian systems.

\section{Conclusions}

Because of their pluripotent properties and the presence of a haploid genome, haESCs can be a powerful tool and a valuable resource in studying gene function. If haESCs could be cultured in a stable manner that prevents diploidization in the future, high-throughput mutated haESC lines would provide more opportunity to study mechanisms behind the development and presence of genetic disorders and susceptibility to diseases. Hence, haESCs can serve as a potentially versatile research tool in many fields, including dosage compensation, long noncoding RNA, XCI escape, and in-vitro meiosis. Based on the developmental potential of haESCs, transgenic animals are easily bred via intracytoplasmic injection. This provides a convenient way to produce numerous homozygous, mutated animals for the study of diseases caused by genetic mutation(s).

\section{Abbreviations \\ CRISPR/Cas: Clustered regularly interspaced short palindromic repeats/Cas; DMR: Differentially methylated region; ESC: Embryonic stem cell; FACS: Fluorescence-activated cell sorting; FSC: Forward scatter; haESC: Haploid embryonic stem cell; SSC: Side scatter; TALEN: Transcription activator-like (TAL) effector nuclease; UV: Ultraviolet; X:A: X chromosome to autosome; XCl: X-chromosome inactivation; Xist: X-inactivation-specific transcript}

\section{Acknowledgements}

The authors thank Dr Q Gu from University of Wollongong for the critical reading of this manuscript.

\section{Funding}

This study was funded by the National Natural Science Foundation of China (31501186 and 31671538 to LS) and the Natural Science Foundation of Tianjin (15JCZDJC65300 to LS).

\section{Availability of data and materials}

Not applicable.

\section{Authors' contributions}

LS and YNL wrote the manuscript. LS revised the manuscript. Both authors read and approved the final manuscript.

\section{Ethics approval and consent to participate}

Not applicable.

\section{Consent for publication}

The authors consent to publication.

\section{Competing interests}

The authors declare that they have no competing interests.

\section{Publisher's Note}

Springer Nature remains neutral with regard to jurisdictional claims in published maps and institutional affiliations.

Published online: 29 September 2017

\section{References}

1. Hartwell LH, Culotti J, Pringle JR, Reid BJ. Genetic control of the cell division cycle in yeast. Science. 1974;183:46-51.

2. Yi M, Hong N, Hong Y. Generation of medaka fish haploid embryonic stem cells. Science. 2009;326:430-3.

3. Leeb M, Wutz A. Derivation of haploid embryonic stem cells from mouse embryos. Nature. 2011;479:131-4.

4. Elling U, Taubenschmid J, Wirnsberger G, O'Malley R, Demers SP, Vanhaelen Q, Shukalyuk Al, Schmauss G, Schramek D, Schnuetgen F, von Melchner H, Ecker JR, Stanford WL, Zuber J, Stark A, Penninger JM. Forward and reverse genetics through derivation of haploid mouse embryonic stem cells. Cell Stem Cell. 2011;9:563-74.

5. Yang H, Liu Z, Ma Y, Zhong C, Yin Q, Zhou C, Shi L, Cai Y, Zhao H, Wang H, Tang F, Wang Y, Zhang C, Liu XY, Lai D, Jin Y, Sun Q, Li J. Generation of haploid embryonic stem cells from Macaca fascicularis monkey parthenotes. Cell Res. 2013;23:1187-200.

6. Li W, Li X, Li T, Jiang MG, Wan H, Luo GZ, Feng C, Cui X, Teng F, Yuan Y, Zhou Q, Gu Q, Shuai L, Sha J, Xiao Y, Wang L, Liu Z, Wang XJ, Zhao XY, Zhou Q. Genetic modification and screening in rat using haploid embryonic stem cells. Cell Stem Cell. 2014;14:404-14.

7. Sagi I, Chia G, Golan-Lev T, Peretz M, Weissbein U, Sui L, Sauer MV, Yanuka O, Egli D, Benvenisty N. Derivation and differentiation of haploid human embryonic stem cells. Nature. 2016;532:107-11.

8. Zhong C, Zhang M, Yin Q, Zhao H, Wang Y, Huang S, Tao W, Wu K, Chen ZJ, Li J. Generation of human haploid embryonic stem cells from parthenogenetic embryos obtained by microsurgical removal of male pronucleus. Cell Res. 2016;26:743-6.

9. Aspberg F, Mertens F, Bauer HC, Lindholm J, Mitelman F, Mandahl N. Nearhaploidy in two malignant fibrous histiocytomas. Cancer Genet Cytogenet. 1995;79:119-22.

10. Shuai L, Zhou Q. Haploid embryonic stem cells serve as a new tool for mammalian genetic study. Stem Cell Res Ther. 2014;5:20.

11. Yang H, Shi L, Wang BA, Liang D, Zhong C, Liu W, Nie Y, Liu J, Zhao J, Gao X, Li $D$, Xu GL, Li J. Generation of genetically modified mice by oocyte injection of androgenetic haploid embryonic stem cells. Cell. 2012;149:605-17.

12. Li W, Shuai L, Wan H, Dong M, Wang M, Sang L, Feng C, Luo GZ, Li T, Li X, Wang L, Zheng QY, Sheng C, Wu HJ, Liu Z, Liu L, Wang L, Wang XJ, Zhao $X Y$, Zhou Q. Androgenetic haploid embryonic stem cells produce live transgenic mice. Nature. 2012:490:407-11.

13. Wan H, He Z, Dong M, Gu T, Luo GZ, Teng F, Xia B, Li W, Feng C, Li X, Li T, Shuai L, Fu R, Wang L, Wang XJ, Zhao XY, Zhou Q. Parthenogenetic haploid embryonic stem cells produce fertile mice. Cell Res. 2013;23:1330-3.

14. Horii T, Morita S, Kimura M, Kobayashi R, Tamura D, Takahashi RU, Kimura H, Suetake I, Ohata H, Okamoto K, Tajima S, Ochiya T, Abe Y, Hatada I. Genome engineering of mammalian haploid embryonic stem cells using the Cas9/ RNA system. PeerJ. 2013;1:e230.

15. Leeb M, Walker R, Mansfield B, Nichols J, Smith A, Wutz A. Germline potential of parthenogenetic haploid mouse embryonic stem cells. Development. 2012;139:3301-5.

16. Barton SC, Surani MA, Norris ML. Role of paternal and maternal genomes in mouse development. Nature. 1984;311:374-6.

17. McGrath J, Solter D. Completion of mouse embryogenesis requires both the maternal and paternal genomes. Cell. 1984;37:179-83.

18. DeChiara TM, Robertson EJ, Efstratiadis A. Parental imprinting of the mouse insulin-like growth factor II gene. Cell. 1991;64:849-59.

19. Reik W, Lewis A. Co-evolution of X-chromosome inactivation and imprinting in mammals. Nat Rev Genet. 2005:6:403-10.

20. Kono T, Obata Y, Wu Q, Niwa K, Ono Y, Yamamoto Y, Park ES, Seo JS, Ogawa H. Birth of parthenogenetic mice that can develop to adulthood. Nature. 2004;428:860-4.

21. Lucifero D, Mertineit C, Clarke HJ, Bestor TH, Trasler JM. Methylation dynamics of imprinted genes in mouse germ cells. Genomics. 2002;79:530-8. 
22. Zhang M, Liu Y, Liu G, Li X, Jia Y, Sun L, Wang L, Zhou Q, Huang Y. Rapidly generating knockout mice from h19-igf2 engineered androgenetic haploid embryonic stem cells. Cell Discov. 2015;1:15031.

23. Zhong $C$, Yin $Q$, Xie Z, Bai M, Dong $R$, Tang W, Xing YH, Zhang $H$, Yang $S$, Chen LL, Bartolomei MS, Ferguson-Smith A, Li D, Yang L, Wu Y, Li J. CRISPRCas9-mediated genetic screening in mice with haploid embryonic stem cells carrying a guide RNA library. Cell Stem Cell. 2015;17:221-32.

24. Li Z, Wan H, Feng G, Wang L, He Z, Wang Y, Wang XJ, Li W, Zhou Q, Hu B. Birth of fertile bimaternal offspring following intracytoplasmic injection of parthenogenetic haploid embryonic stem cells. Cell Res. 2016;26:135-8.

25. Zhong C, Xie Z, Yin Q, Dong R, Yang S, Wu Y, Yang L, Li J. Parthenogenetic haploid embryonic stem cells efficiently support mouse generation by oocyte injection. Cell Res. 2016;26:131-4.

26. Shuai $L$, Wang $Y$, Dong $M$, Wang $X$, Sang $L$, Wang $M$, Wan $H$, Luo G, Gu T, Yuan Y, Feng C, Teng F, Li W, Liu X, Li T, Wang L, Wang XJ, Zhao XY, Zhou Q. Durable pluripotency and haploidy in epiblast stem cells derived from haploid embryonic stem cells in vitro. J Mol Cell Biol. 2015;7:326-37.

27. Safavi S, Forestier E, Golovleva I, Barbany G, Nord KH, Moorman AV, Harrison CJ, Johansson B, Paulsson K. Loss of chromosomes is the primary event in near-haploid and low-hypodiploid acute lymphoblastic leukemia. Leukemia. 2013;27:248-50

28. Kaufman MH, Robertson EJ, Handyside AH, Evans MJ. Establishment of pluripotential cell lines from haploid mouse embryos. J Embryol Exp Morphol. 1983;73:249-61.

29. Leeb M, Wutz A. Haploid genomes illustrate epigenetic constraints and gene dosage effects in mammals. Epigenetics Chromatin. 2013;6:41.

30. Horii T, Hatada I. Genome editing using mammalian haploid cells. Int J Mol Sci. 2015:16:23604-14.

31. Freimann R, Kramer S, Böhmler A, Wutz A. Gewinnung haploider stammzellkulturen der maus für genetische screens. BIOspektrum. 2014;20:416-8.

32. Takahashi S, Lee J, Kohda T, Matsuzawa A, Kawasumi M, Kanai-Azuma M, Kaneko-Ishino T, Ishino F. Induction of the G2/M transition stabilizes haploid embryonic stem cells. Development. 2014;141:3842-7.

33. Guo A, Huang S, Yu J, Wang H, Li H, Pei G, Shen L. Single-cell dynamic analysis of mitosis in haploid embryonic stem cells shows the prolonged metaphase and its association with self-diploidization. Stem Cell Rep. 2017; 8(5):1124-1134.

34. Yilmaz A, Peretz M, Sagi I, Benvenisty N. Haploid human embryonic stem cells: half the genome, double the value. Cell Stem Cell. 2016;19:569-72.

35. Monfort A, Di Minin G, Postlmayr A, Freimann R, Arieti F, Thore S, Wutz A. Identification of Spen as a crucial factor for Xist function through forward genetic screening in haploid embryonic stem cells. Cell Rep. 2015;12:554-61.

36. Li X, Cui XL, Wang JQ, Wang YK, Li YF, Wang LY, Wan HF, Li TD, Feng GH, Shuai L, Li ZK, Gu Q, Hao J, Wang L, Zhao XY, Liu ZH, Wang XJ, Li W, Zhou Q. Generation and application of mouse-rat allodiploid embryonic stem cells. Cell. 2016;164:279-92.

37. Leeb M, Dietmann S, Paramor M, Niwa H, Smith A. Genetic exploration of the exit from self-renewal using haploid embryonic stem cells. Cell Stem Cell. 2014;14:385-93.

38. Zhang S, Teng Y. Powering mammalian genetic screens with mouse haploid embryonic stem cells. Mutat Res. 2013;741-2:44-50.

39. Pettitt SJ, Rehman FL, Bajrami I, Brough R, Wallberg F, Kozarewa I, Fenwick K, Assiotis I, Chen L, Campbell J, Lord CJ, Ashworth A. A genetic screen using the piggyBac transposon in haploid cells identifies Parp1 as a mediator of olaparib toxicity. PLoS One. 2013;8:e61520.

40. Wutz A. Haploid mouse embryonic stem cells: rapid genetic screening and germline transmission. Annu Rev Cell Dev Biol. 2014;30:705-22.

41. Davis EM, Kim J, Menasche BL, Sheppard J, Liu X, Tan AC, Shen J. Comparative haploid genetic screens reveal divergent pathways in the biogenesis and trafficking of glycophosphatidylinositol-anchored proteins. Cell Rep. 2015;11:1727-36

42. Tokunaga M, Kokubu C, Maeda Y, Sese J, Horie K, Sugimoto N, Kinoshita T, Yusa K, Takeda J. Simulation and estimation of gene number in a biological pathway using almost complete saturation mutagenesis screening of haploid mouse cells. BMC Genomics. 2014;15:1016.

43. Blomen VA, Majek P, Jae LT, Bigenzahn JW, Nieuwenhuis J, Staring J, Sacco $\mathrm{R}$, van Diemen FR, Olk N, Stukalov A, Marceau C, Janssen H, Carette JE, Bennett KL, Colinge J, Superti-Furga G, Brummelkamp TR. Gene essentiality and synthetic lethality in haploid human cells. Science. 2015;350:1092-6.
44. Jung CJ, Menoret S, Brusselle L, Tesson L, Usal C, Chenouard V, Remy S, Ouisse LH, Poirier N, Vanhove B, de Jong PJ, Anegon I. Comparative analysis of piggyBac, CRISPR/Cas9 and TALEN mediated BAC transgenesis in the zygote for the generation of humanized SIRPA rats. Sci Rep. 2016;6:31455.

45. Pettitt SJ, Tan EP, Yusa K. Piggybac transposon-based insertional mutagenesis in mouse haploid embryonic stem cells. Methods Mol Biol. 2015;1239:15-28.

46. Okamoto I, Patrat C, Thepot D, Peynot N, Fauque P, Daniel N, Diabangouaya P, Wolf JP, Renard JP, Duranthon V, Heard E. Eutherian mammals use diverse strategies to initiate $X$-chromosome inactivation during development. Nature. 2011:472:370-4.

47. Marahrens $Y$, Loring J, Jaenisch R. Role of the Xist gene in $X$ chromosome choosing. Cell. 1998;92:657-64.

48. Kimura Y, Oda M, Nakatani T, Sekita Y, Monfort A, Wutz A, Mochizuki H, Nakano T. Crispr/cas9-mediated reporter knock-in in mouse haploid embryonic stem cells. Scientific Reports. 2015:5:10710. 